Diplomates, Stage 1 consists of 2 Part II Modules (SAMs) and 1 Part IV Module (PPM or approved alternate).

Diplomates who certified or recertified in 2006 may now begin working on the MC-FP Modules at their convenience. Stage 1 requirements (2 Part II Modules and 1 Part IV Module) are due by December 31, 2009.

In order to help all Diplomates keep track of their progress in MC-FP, the ABFM has updated its Web site to reflect the 7- or 10-year track chosen by the Diplomate. We encourage all Diplomates to visit the ABFM Web site (http://www.theabfm.org) and log in to the physician's portfolio section.

The ABFM has continuously worked to improve the MC-FP process to better serve and communicate with the Diplomates. As part of this process, the ABFM has collaborated with many key organizations to improve all areas of satisfying requirements for relicensure, credentialing, practice reporting requirements demanded by payors, and pay for performance initiatives. As a result of one of these endeavors, the ABFM will begin publicly reporting Diplomate certification status on the Web site to include MC-FP status. This information will begin to appear on the Web site in 2007. The Joint Committee for the Accreditation of Hospital Organizations (JCAHO) recently revised regulations after endorsing and now adopting the same 6 general competencies that the ABFM uses for the assessment of Diplomates who participate in MC-FP. The American Board of Medical Specialties (ABMS) is working closely with the JCAHO to develop a mechanism by which hospital credentialing agencies can verify the Maintenance of Certification status of physicians who apply for privileges within their hospital. This will require modifications to the current verification process on the ABMS Web site and also will necessitate that individual specialty boards report the status of their Diplomates in the Maintenance of Certification process.

Jane Ireland American Board of Family Medicine

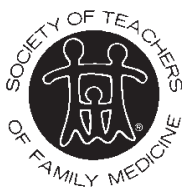

From the Society of Teachers of Family Medicine

Ann Fam Med 2007;5:182-183. DOI: 10.1370/afm.691.

\section{STFM LAUNCHES ITS FUTURE FAMILY DOCS CAMPAIGN-THE SOCIETY'S PREMEDICAL SCHOOL RECRUITMENT PLAN}

STFM is proud to announce the official launch of Future Family Docs, a campaign designed to inspire and support outreach activities by our STFM members to premedical students to promote careers in family medicine. The campaign is organized in 3 ways: (1) a Web site of resource materials to use with students of all ages, (2) a schedule of features in STFM publications, along with discussion and "buzz" at all STFM events, and (3) new partnerships with other organizations who are tackling the same issue of changing the pipeline into medicine. We will promote the importance of mentoring and coaching and exposing young people before medical school to the joys of family medicine. We will target the young people in our own medical practice communities-children from rural communities, children with economic challenges, children of recent immigrant families, and children from minority ethnic communities. This is our next stage of action to fulfill our society's charge from the Future of Family Medicine report, namely, "To Promote a Sufficient Family Medicine Workforce".

At the Web site http://www.futurefamilydocs.org, members can find resources to assist with tackling some local mentoring, recruitment, and student "marketing" campaigns about family medicine. For example, are you thinking about leading a session on primary health care careers in a high school? Our resources include a slide show and a medical school planning guide that you can use for your presentation. We are in the process of building an inventory of STFM member pipeline programs. From this directory, you can contact and learn from STFM colleagues about how they are doing these initiatives, how they are organizing them, funding them, and more. Also on the site are legislative updates related to pipeline activities and inspiring stories and reflective pieces on mentoring, role modeling, and coaching, from the perspective of the mentor or the mentee. The Web site will continue to be filled throughout the year with your contributions. Send some today to our Web site coordinators listed on http://www.futurefamilydocs.org.

We will continue our discussion about this premedi- 
cal recruitment campaign within our membership. At all STFM conferences this year, you will see buttons with "Future Family Docs Rocks!" emblazoned. At the Conference on Predoctoral Education in Memphis, Tenn, at the Conference on Families and Health in Austin, Tex, and at the Annual Spring Conference in Chicago, Ill, we will continue the buzz, highlighting the presentations that focus on mentoring and the pipeline and combing the conference for new programs and creative ideas to share on the Web. We will feature inspiring stories in our STFM Messenger, in Family Medicine, and in our organizational update in the Annals of Family Medicine.

STFM will link to other sister organizations such as (1) the AAFP and its new resource booklet for college and high school students called, "Explore Family Medicine...A Roadmap for Your Future," (2) the AAMC Web site (http://www.AspiringDocs.com), promoting health careers in minority college and high school students, and (3) the National AHEC Web site (http:// www.nationalahec.org), where you can discover AHEC programs that link community children to programs promoting and supporting health careers.

I'd like to recognize the STFM Strategic Task Force Subcommittee for Premedical Recruitment: Terry Steyer, MD; Charles Mouton, MDi Stacy Brungardt, $\mathrm{CAE}_{;}$and the Future Family Docs Web site coordinating group: Dede Willis, MD, MBA, (inventory); Teresa Kulie, MD (stories); Carman Whiting, MD (resources); and Terry Steyer, MD (legislative issues).

I encourage you to jump on board the Future Family Docs bandwagon and check out the Web site today!

Janice Benson, MD

STFM FFM Special Task Force

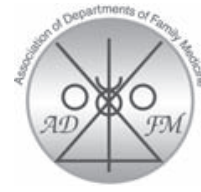

From the Association

of Departments of Family Medicine

Ann Fam Med 2007;5:183-184. DOI: 10.1370/afm.688.

\section{THE AAMC ACADEMIC CHRONIC CARE COLLABORATIVE: FAMILY MEDICINE'S PARTICIPATION AND LESSONS LEARNED}

Beginning in June 2005, a cohort of 48 teams assembled to participate in the first chronic care collaborative that enrolled teams only from the nation's teaching hospitals. The Academic Chronic Care Collaborative (ACCC), formed through a partnership between the AAMC's Institute for Improving Clinical Care and the RWJF's Improving Chronic Illness Care program had dual goals: to improve both the care of patients with chronic illness and the education of health care teams providing care in academic settings.

Specific goals of the collaborative included facilitation of evidence-based improvements, partnership with improvement-focused institutions, identification of improvement innovators practicing in academic settings, convening of these innovators and other experts to craft strategies to move the academic medical community toward better care and learning, and supporting these faculty to develop their academic careers around healthcare improvement.

Teams, representing 22 distinct academic centers, spent the next 15 months implementing changes in the care of selected chronic conditions, including diabetes, asthma, and COPD, using Wagner's Chronic Care Model. Eleven teams were from family medicine training programs, including Southern Illinois University, Lehigh Valley Hospital Network, Harbor-UCLA Medical Center, Duke University Medical Center, University of Colorado Health Sciences Center, University of Cincinnati Medical Center, University of Louisville Health Sciences Center, University of Minnesota School of Medicine, University of South Carolina School of Medicine, NEOUCOM's Summa Health System, Albert Einstein College of Medicine's Montefiore Medical Center, and University of Kentucky Medical School.

The Collaborative, led by co-chairs Dr David Stevens and Dr Ed Wagner and Director Connie Sixta, employed the Breakthrough Series Collaborative learning model developed by the Institute for Healthcare Improvement (IHI), in which multidisciplinary teams attended a kick-off session, 2 face-to-face interactive learning sessions, a virtual learning session, and a congress that coincided with the AAMC Annual Meeting. Between each learning session, teams utilized change packages that were comprised of evidence-based strategies structured around the CCM. Participating teams learned from each other and had access to expert advice.

Departments with participating ACCC teams substantially supported their teams. Participating teams were expected to perform pre-work activities; attend all learning sessions; provide a physician champion; test improvement strategies; use a patient registry to monitor and report outcomes and submit monthly progress reports. Teams were also expected to develop curriculum for learners that paralleled their work in adopting the CCM and to test the impact of these curricular changes.

Early data from the collaborative demonstrate high enthusiasm for this project, as evidenced by the large percentage of on-time monthly reports, high-level participation on monthly conference calls, high reten- 